\title{
LOCAL Y VISITA: \\ EL DOBLE EJE DE JOAQUÍN EDWARDS BELLO
}

\section{Héctor Soto}

Héctor Soto presenta aquí una aproximación a la enigmática personalidad de Joaquín Edwards Bello, el más prolífico de los cronistas nacionales y autor a la vez de varias novelas que, junto con retratar a su clase social, destacaron por la crudeza de su realismo en la indagación del submundo nacional del alcoholismo, la prostitución y la pobreza.

Aunque Joaquín Edwards Bello alcanzó en el país los máximos reconocimientos de su doble oficio (el Premio Nacional de Literatura en 1943 y el de Periodismo en 1959), fue una figura algo descentrada de su clase y también de su tiempo. Escritor inagotable y hombre de grandes contradicciones y fisuras, hay elementos de juicio — señala Héctor Soto- para suponer que tuvo una infancia feliz, una juventud dorada y una vida adulta tan aventurera como turbulenta, tan jugada como inestable. Aun cuando su segundo matrimonio debe haber sido para él un remanso, vivió perturbado por heridas y fantasmas que se volvieron patentes luego de su ataque de apoplejía en 1960. A pesar de haber sido el chileno con más mundo de su época — se sostiene en estas páginas- los escritos de Edwards

Héctor Soto. Abogado y periodista. Crítico de cine. Editor asociado de cultura del diario La Tercera. Autor de Una vida crítica, 40 años de cinefilia (Alfaguara, 2008).

* Versión extendida de la presentación del autor el 15 de octubre de 2009 en el marco del ciclo para estudiantes "Volver a leer”, organizado por el Cep.

Estudios Públicos, 118 (otoño 2010). 
Bello atrapan — para bien o para mal, quiéralo él o no lo quiera- un Chile que habiendo cambiado mucho en las últimas décadas mantiene, sin embargo, fuertes lazos con su identidad y con su historia.

Palabras clave: Joaquín Edwards Bello; literatura chilena; periodismo.

Recibido: enero 2010.

Oon varias las razones que tienen de vuelta en la escena cultural a Joaquín Edwards Bello (JEB). Más de alguien pondrá en duda si es cierto que alguna vez se fue, lo cual puede ser exacto desde la perspectiva mítica. Pero en términos de estricto realismo no lo es, porque es evidente que está siendo poco leído. Ahora el cuadro cambió. La reedición de algunas de sus novelas y los dos tomos con sus Crónicas Reunidas —iniciativa de la Universidad Diego Portales, dos volúmenes excepcionales, arriba de dos mil páginas en total- devuelven al que seguramente es el mejor de los cronistas que ha tenido Chile. También el más prolífico. Estas recopilaciones llegan por ahora sólo hasta el año 1930, pero este proyecto editorial, de muy largo aliento, hijo de la bendita obstinación de Matías Rivas y Roberto Merino, está llamado a ocupar probablemente más que un anaquel de las bibliotecas. Por su envergadura y aliento, en realidad es un acontecimiento editorial tanto para el periodismo como para la literatura chilena.

El año 2004, por otra parte, nuestro premio Cervantes, Jorge Edwards, sobrino suyo, seguramente no el más querido pero al final el único de su familia que perseveró en el mundo de las letras, reivindicó la figura, la vida y las contradicciones de su tío Joaquín en una novela apasionante —El inútil de la familia (Alfaguara)— que está entre las mejores que ha escrito.

Hombre atormentado, gran triunfador en algunos planos, gran derrotado en otros, precisamente por ser una figura llena de fisuras y contradicciones, Edwards Bello interesa y recobra imprevista actualidad. Parece increíble que haya nacido en Valparaíso no tan a fines del 
siglo XIX, cinco años antes de la revolución del 91, trauma que su familia vivió desde el bando parlamentario, porque en sus rupturas y observaciones, en su tono y su desenfado, es difícil hallar una voz más moderna que la suya. En una época en que la crónica estaba devorada por la solemnidad y la retórica, cuando los textos de casi todos los cronistas de su tiempo se caen de las manos y cuando para sobrevivir había que respetar a los poderosos, ponerse en la fila, repetir las verdades oficiales y moverse dentro de los espacios demarcados por la elite, Edwards Bello fue insolente, olímpico, autónomo, excéntrico, original y atrevido.

¿También valiente? Sin duda, un timorato, un joven talentoso pero cautivo de su perfil de socialité, no hubiera llegado a ninguna parte. Sin embargo eso no lo explica todo. Edwards Bello no se entiende sino a partir de su superioridad de clase, de su mirada entre irónica y despectiva a los usos de la sociedad de su tiempo; no se entiende sino en función de la seguridad que debió haberle proporcionado ser mucho más viajado, cien veces más mundano y mil veces más leído que cualesquiera de los próceres de su tiempo que calificaba en el corto listado de la gente protegida por la ventaja o el privilegio de redes sociales extendidas. Las crónicas de Edwards Bello son un extraño equilibrio entre insolencia y clase. La pura insolencia en Chile sirve de poco y no lleva muy lejos: lleva a lo más a la disociación, a las catacumbas, al Chile contestatario, al movimiento okupa, a la disconformidad metódica, majadera y profesional. Y por mucho que la clase sin mucha inteligencia ni arrojo tenga mejor desenlace —una familia bonita, misa de réquiem quizás si con tres curas en el barrio alto y un sentido obituario en la prensa - lo cierto que a la larga también se vuelve completamente intercambiable.

Como Edwards Bello calificaba en uno y otro plano con sobrada autoridad, sus crónicas eran leídas, respetadas, seguidas, lamentadas, rechazadas, discutidas y resentidas. Era leído —escribió alguien de su época- hasta por los lustrabotas. Al margen de ser varios los grupos que se sintieron traicionados por las indiscreciones a que su autor llegó con la publicación de su primera novela —El inútil—, traicionados porque vieron en ella un acto de deslealtad flagrante, también son muchos los que nunca le perdonaron su autonomía de juicio, su ironía, su mirada entre condescendiente y perdonavidas sobre los hábitos, los 
prestigios, los valores y las complicidades dominantes en el Chile de entonces.

En principio lo tuvo todo para ser feliz: cuna, familia, salud, contactos, presencia física y fortuna. ¿A título de qué complicarse la vida con las palabras? Reuniendo tantos atributos para la felicidad, Alone, el gran crítico literario de la época, que posiblemente nunca llegó a tenerle gran simpatía, entre otras cosas porque la rebeldía en casos como el suyo o el de Huidobro siempre le pareció una bravuconada de clase, nunca pudo entender muy bien por qué se había dedicado a escribir: "Con la mitad, otros se hubieran contentado y puestos a disfrutarlos, saboreándolos”' . La gente demasiado feliz efectivamente no necesita complicarse la vida con la literatura: Borges decía no estar seguro de si se escribían novelas en el infierno, pero agregaba que no le cabía duda alguna en cuanto a que en el paraíso no se publicaba ninguna ${ }^{2}$.

Aunque toda vida les debe a las circunstancias mucho más de lo que el género literario de la biografía estaría dispuesta a aceptar — de hecho, las biografías suelen ser el puntual cumplimiento de un plan urdido por una voluntad de hierro, ejecutado con la complicidad del destino-, el libreto de los días de Joaquín Edwards Bello se sale de control cuando en 1904 debe interrumpir sus estudios a raíz del traslado de la familia a Europa. Tenía 17 años y había hecho sus primeros estudios en el colegio Mac Kay, en los tiempos en que funcionaba no en Viña del Mar sino en el Cerro Concepción, y en el Liceo de Hombres de Valparaíso, después Liceo Eduardo de la Barra. Al parecer también pasó fugazmente en algún momento por los patios de los Padres Franceses.

La familia decidió el viaje no para acatar el rito de una larga temporada de residencia en Europa, que era propio de las familias pudientes de la época, sino esperanzada en encontrar mejores respuestas médicas a la enfermedad del padre. Sin embargo, no hubo caso. En

${ }^{1}$ Alone, citado por Francisco Coloane en el prólogo a la edición de Obras escogidas de Joaquín Edwards Bello (1971), p. 24. Bien podría tratarse del prólogo más heterodoxo jamás escrito en Chile. Coloane, además de hacer una introducción general al libro, entrevistó a la viuda del escritor, la señora Marta Albornoz, y transcribió textualmente reseñas y críticas literarias de la época, fragmentos de coloquios y entrevistas, de discursos y necrologías. Su trabajo también incluyó una cartilla bibliográfica y una cronología de la vida de JEB. Lo que se diría "un prólogo enciclopédico".

2 J. L. Borges, “The Art of Fiction”, 1967. 
mayo de 1905 Joaquín Edwards Garriga, prominente banquero y hombre de negocios, no pudo superar la última de las recurrentes crisis a que el cáncer lo estaba enfrentando y falleció en París. Millonario, descendiente de una familia de financistas y diplomáticos, aristocrática aunque de cuño liberal, dejó una familia compuesta por la viuda, Ana Luisa Bello Rozas, nieta de don Andrés Bello, y por sus hijos Joaquín, Emilio, más tarde diplomático, y Delfina, que nunca volvió a Chile y vivió toda su vida en París, casándose primero con un noble francés y más tarde con un prestigioso pintor de sociedad.

Con la idea de completar su formación y prepararlo para la vida diplomática con la que todos estaban de acuerdo — todos, es decir, su madre y sus tíos, pero no él, por cierto- Joaquín es enviado a Londres, al colegio privado Sulhumpstead Rectory, en Theale, donde permanece por algo más de un año, hasta que en agosto de 1906 un nuevo imprevisto se interpone en el proyecto que la familia había previsto para él: el terremoto de Valparaíso. El grupo debe retornar a Chile y lo hace a fines de ese año, dando por concluida con sentimientos de contrariedad una experiencia doblemente malograda. Decir que el regreso abortó la preparación del escritor y cronista para la vida diplomática sería un abuso del lenguaje; de hecho, nadie mejor que él mismo sabía que sus intereses iban por otro lado.

Que la muerte del jefe de familia lo haya puesto a él junto a su mamá en la primera línea del manejo de los asuntos familiares fue tanto un accidente como una fuente de tensiones. Al poco tiempo quedó en claro, en términos de viajes y derroches, de fiestas y casinos, que los resguardos para una administración aplicada y prudente no eran lo suyo. Sus talentos iban en otra dirección y se manifiestan, con notoria sorpresa para su entorno más próximo, con la publicación de su primera novela, El inútil, en septiembre de 1910, justo cuando el país está celebrando su primer centenario. Como la ficción guarda varios puntos de contacto con la realidad, no tarda en sobrevenir el escándalo. ¿Qué? ¿Que a Joaquín ahora se le ocurrió publicar? ¿Estamos hablando del mismo? ¿Y con qué autoridad se atreve a hacer escarnio de su familia, de sus amistades, de su clase?

La jugada no le salió gratis. Reproches, vetos, censuras, satanizaciones. Defraudada, la familia decidió que la mejor manera de protegerlo mientras pasaba el chaparrón era el autoexilio y fue así como viajó a Río de Janeiro. La fuga terminó siendo bastante más larga de lo 
prevista. Aunque en Río no pudo quedarse más de tres meses, después volvió a Santiago intempestivamente y al cabo de muy corto tiempo emprendió un largo viaje a Europa, ahora para vivir en el Viejo Mundo, ya no como estudiante sino como vividor, las experiencias de las cuales la orfandad lo privó seis años antes.

Volverá a Chile mucho después, cuando ya ha pasado la curva de los 30 años, ingresando a la planta periodística del diario La Nación. El diario todavía no era propiedad del gobierno y Edwards Bello entró por la puerta ancha, bajo la protección de don Eliodoro Yáñez, el fundador, papá de Juan Emar. Ahí se mantendrá como editor y redactor hasta 1930, cuando prefiere salirse de la organización luego que la típica aplanadora oficialista lo perjudica. Pero va a seguir colaborando en condiciones relativamente privilegiadas en La Nación hasta el final de sus días, atravesando administraciones, vaivenes políticos, gobiernos y ciclos de furor y de contracción. También escribiría por algunos períodos para el vespertino Los Tiempos — filial del diario oficialistay para los diarios La Patria de Concepción y El Correo de Valdivia.

Salvo por sus notables crónicas literarias y urbanas, que había leído en Apsi y probablemente también en La Época, en 1996 yo no conocía mucho a Roberto Merino, el mejor especialista en Edwards Bello y el gran custodio de su memoria. Pero sí tenía claro que quería contar con colaboraciones suyas para la revista Capital, de la cual fui editor por más de una década y que por ese tiempo estaba dando sus primeros pasos.

Me junté con Roberto para explicarle el tipo de artículos que esperaba de él y no recuerdo que me haya llamado mucho la atención que él me propusiera encontrarnos en la sección Referencias Críticas de la Biblioteca Nacional. ¿Por qué ahí, me vine a preguntar después? ¿Sería porque ya le había dicho que quería que su primer artículo fuera sobre el Marqués de Cuevas, gran amigo de Edwards Bello? ¿Sería porque a lo mejor Roberto estaba trabajando en esa sala y le resultaba cómodo no tener que trasladarse? No tengo idea. Lo que sí sé es que Roberto aprovechó ese día de mostrarme las cajas — ninguna mucho más digna que cajas de zapato- que contenían el archivo de Joaquín 
Edwards Bello y no creo que haya podido medir la conmoción interior que ese material, esa revelación, me produjo.

Si cuento esto es porque la experiencia me pareció portentosa. Fue literaria, fue periodística, pero también diría que fue cívica. Ahí estaba desplegado ante mis ojos el más delirante, arbitrario, grandioso y detallista archivo de recortes que en Chile alguien haya podido hacer, mantener y llevar. Miles y miles de recortes, algunos pegados con engrudo a una cartulina, otros adheridos con scotch ya reseco a una simple hoja de papel carta, los más grandes simplemente corcheteados aunque doblados con cariño, algunos bien conservados, otros no tanto, cada cual con su fuente, su fecha y no pocos con anotaciones laterales varias. Observaciones de distinta época con lápiz de grafito, con tinta, con lápiz a pasta.

Lo que Roberto Merino me estaba mostrando no era sólo un monumento informático anterior a la informática, con entradas tan arbitrarias o locas como "Pipas”, "Madrid”, “Adán”, "Banderas” o "Escritores”. En muchos sentidos, era toda una vida, o parte sustantiva de una vida. En muchos sentidos también, era la cocina intelectual de un cronista formidable que publicó en vida arriba de 12 mil artículos, algunos de ellos bastante largos, con una dinámica y frecuencia que incluso al día de hoy, cuando se escribe con computador y no a mano como lo hacía él, pondría en apuros a cualquier grafómano y podría pulverizar hasta al cronista de prosa más rápida, fácil o inspirada. No en último lugar, ese conjunto de recortes con información relevante y valiosa para alimentar el oficio, sistematizado con el esmero de un periodista aplicado y el candor de un niño que trata de dominar las manualidades de la tijera, la goma y el engrudo, hablaba de un modo indirecto, oscuro, de las grandezas y estrecheces de un Chile ido, en el cual nada era fácil, nada fue gratis y nada cayó del cielo.

Edwards Bello dedicaba sus buenas horas al día a alimentar y actualizar tijera en mano su archivo. "El caso es que vivo en mi archivo” —escribió en 1954- " "Gasto en él dos o tres horas cada día. Mi archivo vale más que mis escritos. Es mi obra maestra. Es modesto, sin presencia, decente"3. Hay quienes dicen que el que está en la Biblioteca Nacional no es el primero que hizo. Habría tenido otro con anterioridad, que en algún momento habría tenido que vender. Es posi-

3 JEB, crónica “El Archivo”, 1954, citado en Obras escogidas, 1971, pp. 619620. 
ble. Lo que sí se sabe es que le gustaba levantarse temprano y escribir su crónica incluso antes de desayunar. También solía pintar a esas horas y uno se pregunta dónde diablos estarán esas pinturas o dibujos en la actualidad.

Al margen de su nutrida producción de novelista —las suyas deben ser unas doce novelas en total- y de su no menos significativa fecundidad como ensayista y divulgador, puesto que publicó muchos opúsculos, biografías y libros con olor a proclama, el archivo de Edwards Bello fue una pieza fundamental de su producción si se tiene en cuenta que en promedio y por lo bajo publicó una crónica diaria de lunes a viernes durante casi cuarenta años. Como ritmo, frenético. Como conjunto, una barbaridad.

No es casualidad que Edwards Bello haya encontrado en la crónica —el más híbrido de los géneros periodísticos - un terreno receptivo a su carácter y sensibilidad. La crónica tiene algo de información, algo de relato, algo de ensayo y algo de eso que los periodistas llaman magazine. La crónica supone punto de vista y alguna habilidad para el manejo de las emociones. El buen cronista aporta datos nuevos, entretiene, compara, describe una situación, opina muchas veces de contrabando y trata de emocionar o de convencer. Pero lo suyo no tiene nada que ver con la moderna profusión en la prensa de la columna de opinión, donde alguien fija su parecer frente a un hecho o hace una lectura interpretativa y más o menos articulada sobre el acontecer. Menor relación todavía tiene con lo que hacen los opinólogos, que se limitan a decir —a decir, no a explicar— por qué sí la mermelada de damasco y por qué no la de mora. La crónica, en cambio, supone información a veces dura y a veces blanda; exige por lo general un planteamiento, un desarrollo y un desenlace y es difícil que se haga viable sin un tono de complicidad mínima con el lector. Para escribir crónica hay que saber contar, saber relacionar y también saber sorprender.

Edwards Bello dominó con elegancia incomparable esas artes. Por eso se sigue leyendo sin problemas. Es leve y sugerente. Es divertido y escéptico. Es entusiasta y perverso. Es mundano al mismo tiempo que terriblemente chileno. Sobre todo, es directo, no se va por las ramas. Podrá haber envejecido en algunos de sus argumentos de autoridad, pero se vacunó desde temprano contra tres de las peores y más frecuentes pestes en el gremio de los cronistas: la pedantería, el proseli- 
tismo y la egolatría. La pedantería puede convertir cualquier crónica, así sea de apenas una carilla, en un ladrillazo. El proselitismo lleva a que el cronista tenga agenda propia y no dé puntada sin hilo con tal de acarrear aguas a molino, redimiendo a los infieles o salvando almas para su causa. Y, bueno, sobran los casos en los cuales la hipertrofia del ego termina por dejar al cronista completamente inválido. Difícil determinar cuál pesadilla es peor.

Entretenido y liviano, multifacético y agudo, cronista capaz de levantar una catedral a partir de un solo detalle o de comprimir tres siglos de historia en un solo párrafo, Edwards Bello quizás no tuvo eso que hoy día llamaríamos un eje. Nunca sirvió una causa muy definida y mucho menos tuvo un sentido misional en su trabajo. Tuvo sí ciertos rasgos que nunca lo abandonaron: curiosidad intelectual, sentido de la paradoja, humor y una mirada que siempre se extendió más allá de las ocho manzanas del centro, más allá de las cincuenta familias que cuentan y más allá también de las provincianas fronteras intelectuales del Chile de la primera mitad del siglo XX. El hecho de no escribir de política - ¿con qué independencia lo hubiera podido hacer en un diario que finalmente pasó a ser propiedad del gobierno?- le permitió ver un poco más allá del metro cuadrado en que tarde o temprano termina plantándose el columnista político.

Eso no es todo. La otra constante de sus crónicas es un cierto enojo, una cierta amargura, a lo mejor incluso un cierto resentimiento con Chile. ¿Contra qué y contra quiénes? Bueno, en principio contra la clase donde había nacido; contra lo que él sentía con alguna cuota de soberbia como mediocridad nacional; contra la gente demasiado espléndida; contra la patanería chilena. Contra todo, si es necesario.

Edwards Bello continuamente está comparando: Santiago no es París; lo que acá creemos fino afuera no pasaría de ser una rotería; lo que aquí tenemos por bueno, en el Viejo Mundo se toma simplemente por basura; los que son importantes en Santiago en Madrid son unos pobres diablos o provincianos de solemnidad... Los coscorrones no paran. No hay que ser un gran psicoanalista para señalar que Edwards Bello tiene una herida, un desencuentro profundo con la sociedad chilena. En una zona, reivindica la emoción de Chile con el ímpetu del más ferviente de los patriotas. En otra, descalifica al país donde pueda y como pueda, venga o no venga al caso. 
Es obvio que fue acumulando una buena cantidad de cuentas pendientes con Chile. Con la falta de realismo propia de quien prefiere ser enfant terrible y exige ser querido incondicionalmente por eso, nunca pensó que iba a ser repudiado por los suyos. Ocurre además que cuando publicó El inútil la situación de su familia ya no estaba en muy buen pie. Se tiene que ir del país, pero a la vuelta de ocho años tiene que volver. Y ya no es el dandy ni el joven rupturista, revoltoso y dorado que se había ido. Ahora tiene que trabajar, que ganarse la vida, que vivir en un ambiente sustancialmente menos refinado y glamoroso que el suyo de antes. Ha ganado quizás en mundo, en madurez intelectual, en seguridad interior. Pero, habiendo hecho sonar en los casinos europeos o, antes de haber partido, en garitos locales, dos o tres fortunas, su peso en términos de inserción y de patrimonio ahora era menor.

Nunca lo perdonarían. El desajuste es enteramente explicable por lado y lado. Edwards Bello se siente vetado o subestimado. Y su grupo de pertenencia, bueno, dolido, en función de una lógica gruesa pero inapelable: si haces mofa de nosotros entonces no cuentes con nosotros. El rencor y la desconfianza son recíprocos. Los alimentan los sentimientos de ingratitud y también tanto el tono de las crónicas como el desprecio apenas encubierto que trasuntan novelas suyas contra la gente bien, contra los millonarios, contra damas encumbradas y beatas y contra los señorones que están al mando de la tribu. Si Chile tiene algún destino, cree Edwards Bello, es por los valores que puedan quedar en la base de la pirámide social —en los rotos, en las clases que la pobreza y el alcoholismo están disociando y destruyendo- y no por los que la indolencia y la codicia nacional hicieron desaparecer de la cúpula. Hay que decirlo: a diferencia de lo que hacía en las crónicas, en sus novelas Edwards Bello era sensible a la moral de la redención social. Querían enseñar, moralizar, redimir, salvar el mundo, y probablemente a este factor, más que a cualquier otro, se debe que no hayan terminado envejeciendo muy bien.

\section{III}

Es una ironía que en la misma medida en que fue afirmando su pulso como cronista y ampliando sus registros como escritor, Edwards Bello haya ido en su vida cerrando puertas hasta convertirse para los 
suyos, primero, en un sospechoso, luego en un francotirador, después en un excéntrico de arrebatos misántropos y finalmente en un fantasma.

Como cambió de barrio, de clase social, de familia, y aun de sangre y pasado — según él mismo lo reconoció de acuerdo a la espléndida cita de una de sus crónicas que Jorge Edwards consigna en El inútil de la familia - , queda en definitiva la duda sobre si terminó bajando al mundo popular, el de las diversiones plebeyas, el de las amistades de bar, el de los coqueteos con señoritas graciosas y de ojos vivarachos, por una o más de las siguientes razones: por despecho o porque ese mundo era en verdad el único que genuinamente le gustaba o porque tal vez se dio cuenta que a esas alturas ya no tenía otra alternativa. El asunto no es tan simple ni se explica únicamente por una cuestión de recursos. Edwards Bello nunca fue un personaje de una sola pieza. Cuando en 1921 contrae matrimonio con una española —Ángeles Dupuy Ruiz de Alarcón- es un secreto a voces que ella provenía de una clase social inferior a la suya. Ese matrimonio duró poco. Después de darle dos hijos, la esposa murió sorpresivamente en septiembre de 1926. Nunca quizás había sido muy dichosa. Siendo desde todo punto de vista impresentable que jamás la sociedad chilena la haya acogido con receptividad, mucho peor es el dato de que él tampoco la tratara con especial cariño o delicadeza.

Después de esa experiencia, pasó mucho tiempo antes que lograra rearmarse emocionalmente. Quizás no lo necesitaba. En los años 40 su estrella fue en ascenso y lo acompañó más que bien. Tenía un público fiel que lo seguía y cuando Jorge Coke Délano llevó al cine en 1941 su novela La chica del crillón su nombre quedó asociado a un acontecimiento. Dos años más tarde se reeditó su novela Valparaíso, ciudad del viento con el título de El viejo Almendral. El mismo año, 1943, recibe el Premio Nacional de Literatura, por cuyo establecimiento se la había jugado a fondo en sus artículos años antes. Fue un buen período para él en términos de influjo y reconocimiento.

Vino a darse cuenta ya bien mayor de la necesidad de tener un hogar. Cuando se casó el 19 de marzo de 1953, era un señor con sus buenos 66 años. El matrimonio coincidió con su mudanza al modesto caserón de calle Santo Domingo abajo — barrio Brasil— donde terminaría sus días. Su señora, Marta Albornoz, viuda y madre de un hijo, era mucho menor que él y la había conocido de niña en el barrio Maruri, 
donde el padre de ella tenía un emporio. Después, cuando hizo sus humanidades, entró como secretaria en el Departamento de Extensión Cultural de la Universidad de Chile, en los tiempos en que en esta repartición trabajaban Neruda, Marta Brunet, Antonio Acevedo y Edwards Bello, entre otras celebridades. Salieron por un tiempo, pero la relación terminó de manera abrupta cuando él se casó con la española. Al poco tiempo ella también se casó, en parte porque encontró al hombre indicado y en parte para rehacerse de lo que siempre consideró "una chanchada”. Volverían a encontrarse mucho después. Una versión sin confirmar la pone a ella atendiendo mesas en El Naturista, restaurant céntrico al cual el escritor iba a almorzar en busca de alguna sopita sana que pudiera aliviar sus congestiones estomacales, y que después fue a preparárselas a la casa. No sé si sea verdad. Como sea, doña Marta fue su tabla de salvación en términos de apoyo y compañía, de cariño y contención. Con ella pudo redescubrir las nociones de intimidad y de hogar, dulcificando el mundo extremadamente duro en que se había estado moviendo como señor excéntrico, como figura un tanto teatral que cruzaba todos los días el centro de Santiago sin mirar a nadie y como cliente habitual del bar La Bahía, en cuya animada barra, al fondo, instaló prácticamente su oficina durante una época. La Bahía ya en sus tiempos era un bar que había conocido tiempos mejores. Ubicado prácticamente al lado de la Casa Colorada, hoy un edificio-caracol de los más horrorosos del centro, el inmueble en el pasado había sido — que nadie rasgue vestiduras si es que es cierto que la historia es circular - la casa de su abuela materna, el mismo lugar donde el escritor muchas veces alojó siendo niño.

Debe haber terminado siendo — qué duda cabe — un viejo arisco, un tanto maniático y llevado de sus ideas. No saludaba. No hacía visitas y tampoco las toleraba. Le cargaba estar sentado mucho rato. Despreciaba el gusto del chileno medio. Era difícil sacarlo de una mesa de juegos. Nunca dejó de vestir como caballero distinguido: buenos cortes, lanas inglesas, sombreros de calidad y todos los pequeños detalles de alguien que no se quiere quedar atrás en las pistas de la elegancia. Tenía opiniones políticamente muy incorrectas sobre la flojera y el alcoholismo del indio chileno y sobre la estupidez chismosa de las mujeres. Huía de los lateros como de la peste y era capaz de cambiarse de vereda para no encontrarse con gente que le caía mal. Se descompensaba con los gazapos y, como mandaba al diario los textos 
escritos a mano, tenía que entregarse a la voluntad, cultura y buena vista del linotipista; por lo mismo, con frecuencia, lo pasaba muy mal. En esto no era muy distinto de "Marcel Proust, que se retorcía como gusano cortado en dos cuando sorprendía una coquille en su universo literario”4, como él mismo escribió. ¿Por qué diablos si había escrito "una mujer jirafa con ojeras negras" aparecía publicado "una mujer jirafa con orejas negras”. ¿’or qué si ponía "pudendas” aparecía "prudentes” y por qué "frazada” por "zafada”? Los banquetes le parecían un suplicio. Aunque agnóstico, creía en lo que llamaba la Vida Descarnada, una suerte de supervivencia de la inteligencia, las ideas y los libros. Le gustaba tomarse fotos en las plazas públicas. Pensaba que Santiago podía ser una ciudad tan horrible como El Cairo y que los chilenos profesábamos el culto al imbunche y al feísmo nacional. Era hombre de juicios literarios rotundos: "Con los mayores respetos para los maestros Blest Gana y Orrego Luco, declaro que no volvería a leer Martín Rivas ni Casa Grande como no fuera para hacer penitencia, en Semana Santa”. Odiaba los libros soporíferos y decía que algunos textos criollistas deberían venderlos en las boticas como remedio para dormir.

Lo terrible es que los años fueron minando la seguridad que irradiaban muchas de estas sentencias, excentricidades y rarezas. Mucho peor, la apoplejía que sufrió en 1960 fue para él devastadora. No sólo quedó inválido y con la mitad del rostro paralizado. El ataque llegó poco después de haber recibido en 1959 el Premio Nacional de Periodismo y cuando parecía que su vida estaba entrando a lo que se perfilaba como una etapa de gozosa estabilidad. Cinco años antes había ingresado a la Academia Chilena de la Lengua en una sesión a la que concurrió —no se pierdan— el Presidente de la República, Carlos Ibáñez. Tras el zarpazo vascular, gracias a su tenacidad y a las terapias naturistas del doctor Manuel Lazaeta Acharán — cataplasmas de barro, compresas de agua fría, infusiones de yerbas silvestres, que fueron durante décadas la medicina económica de la clase media chilena, antes que los fármacos, los médicos, la Fenatach y las isapres convirtieran la salud en un tema de nunca acabar- el escritor recuperó parcialmente

\footnotetext{
${ }^{4}$ JEB, crónica "Editores y Erratas", recogida en JEB, En torno al periodismo y otros asuntos, 1969, pp. 143-147.

${ }^{5}$ JEB, citado por Francisco Coloane en su prólogo a la edición de Obras escogidas de Joaquín Edwards Bello, 1971, p. 14.
} 
el movimiento y pudo escribir y caminar un poco. Pero se volvió cada vez más inseguro de lo que le esperaba. Inseguro hasta la paranoia. El futuro no podía ser sino peor. Y si antes había sido un marido terriblemente celoso (escondido detrás de los árboles o de los postes vigilando los pasos de su mujer mientras ella atendía el negocio y peluquería que su papá le había puesto en el barrio Brasil), el terror de ser abandonado comenzó a ser una pesadilla cada vez más recurrente.

Faltándole sólo meses para los 81 años, el 19 de febrero de 1968, prefirió terminar con esa cadena de humillaciones y bajezas y, empuñando el revolver Colt calibre 38, arma que su propio padre le había regalado antes de morir, "para que se protegiera”, aprovechando un minuto de ausencia de su esposa, decidió poner fin a sus días con un tiro en la boca. "Perdóname lo mucho que te hago sufrir. Si me voy es culpa exclusiva mía. Perdóname. Yo no puedo más con esta tremenda agonía”, le había escrito a su esposa.

Un hombre puede contra su época. Está probado que también puede contra su clase. Eventualmente puede incluso contra su familia. Pero contra sí mismo, sobre todo en la ancianidad, ya es más duro.

\section{IV}

Hijo de una época que asistió a lo que parecía ser el derrumbe definitivo de la vieja democracia liberal en la Europa de entreguerras, miembro de una generación que indistintamente mezcló la tentación estatista con la exaltación de la raza, el fuego nacionalista con una conciencia social más o menos alarmada ante el espectáculo de un bajo pueblo que estaba siendo destruido por la pobreza, el desarraigo, el alcoholismo, la criminalidad y la prostitución, además de ciudadano de un país cada vez más dividido entre su debilidad por las Milicias Republicanas, de un lado, y su fascinación, del otro, por los puños en alto del proletariado emergente segregado por un cinturón de pobreza en torno a todas las ciudades chilenas, Joaquín Edwards Bello fue tironeado ideológicamente por diversas fuerzas y desde distintos lados. Aunque nunca se compró del todo las patrañas racistas y arauco-góticas de Nicolás Palacios sobre la nacionalidad, fue capaz sin embargo de rei-

${ }^{6}$ JEB, citado por Francisco Coloane en su prólogo a la edición de Obras escogidas de Joaquín Edwards Bello, 1971, p. 12. 
vindicar una entelequia parecida —el conjunto andino-sísmico- como matriz regeneradora del gran desquite de las frustraciones patrias y el gran motor de una impostergable movilización nacional.

No hay duda de que también fue sensible a los vientos de reconocimiento y exaltación de la identidad latinoamericana que soplaron sobre la región en los años 30. No fue inmune al discurso encendido de figuras como Lázaro Cárdenas, en México, o como Víctor Raúl Haya de la Torre, en Perú, que por lo demás celebró con emoción sus planteamientos. El título de uno de sus ensayos, Nacionalismo continental, de 1925, es revelador. También hizo algunas aproximaciones inorgánicas y parciales al nacionalsocialismo. Tiene que haberlo impresionado la velocidad con que Alemania recuperó la disciplina colectiva y el orgullo nacional en la década del 30. Pero sus escarceos con el pensamiento nazi fueron de naturaleza más emocional que racional, lo que no obsta para que al comenzar la segunda guerra mundial simpatizara más con los países del eje que con las naciones aliadas.

No cabe duda que la prosa diáfana y ocurrente de sus crónicas ha resistido el paso del tiempo bastante mejor que los trazos confusos y un tanto erráticos de su pensamiento político. Aunque se declaraba liberal y admirador fervoroso del gran Vicuña Mackenna, era un portaliano confeso y se la jugó siempre por un presidente fuerte. Aunque no tenía nada de balmacedista — de hecho, su familia fue parte del núcleo duro de la rebelión contra el mandatario y sufrió apremios durante el conflicto por eso mismo-, llegó a detestar el sistema parlamentario. Aunque decía que nada importante podía salir de América latina mientras la región continuara limitándose a copiar lo que venía de Europa - copiar las ciudades, copias las novelas, copiar las ideas políticas-, es a lo menos significativo que buena parte de su producción periodística haya mirado y medido la realidad nacional con estándares foráneos que tributaban mañana, tarde y noche precisamente al Viejo Mundo. Es probable que asimetrías como éstas respondan a evolución: nadie, salvo un demente, puede pensar lo mismo durante medio siglo. Pero es probable que se trate pura y simplemente de inconsistencias. ¿Por qué la crónica de hoy tiene que rendirse a la ortodoxia de la crónica de ayer?

"Me cuesta a veces creer en los chilenos - dijo en el curso de un coloquio un año antes de morir-. Si me dicen que hay una gran novela de amor que se desarrolla en Chiloé, exclamo: no puede ser. 
Para amores, Florencia, París, Roma. Chiloé, no, por ningún motivo”7. Nadie diría que es un americanista fervoroso o el rey de los valores autóctonos el que está hablando. Pero, inteligente y atravesado por contradicciones múltiples, inteligente en los alcances que le daba a la palabra Scott Fitzgerald, capacidad para funcionar no obstante manejar ideas contradictorias en la cabeza, en una circunstancia parecida, otro coloquio público, hizo esta maravillosa confesión: "Soy muchos seres. Cada uno piensa y actúa de un modo. Soy el que cruzó a caballo el túnel, el que atravesó la cordillera a lomo de mula. El de las chayas y el de las casas malas de niñas buenas. El de Quilpué y el de París. El de las mesas de juego. El que hoy no puede caminar, ni pensar, ni nada. Whitman ha dicho que él lleva a todos los hombres adentro. No me reprochen. No sé cuál Joaquín Edwards habla y cuál escucha. Son muchos" 8 .

Mientras muchos de los grandes prestigios de su época se han estado debilitando año tras años en el último tiempo — desde Mariano Latorre a Víctor Domingo Silva, desde Orrego Luco a Salvador Reyes - la imagen de Edwards Bello no ha hecho más que fortalecerse y crecer. Hace poco, Juan Manuel Vial, en La Tercera, comentando el segundo tomo de sus crónicas reunidas decía que hacia 1930 el doble Premio Nacional "ya era el padre de la patria literaria”9. Y Pedro Gandolfo en El Mercurio reconocía en su obra un conjunto de atributos que pocos escritores chilenos, de antes y de ahora, aprobarían a la primera: "agudeza, inteligencia, sentido del humor, crítica pertinaz, personajes entrañables, historias bien contadas, viajes, algo de nostalgia"10.

No siempre, claro, fue así. Los críticos de su época pusieron sobre todo atención a los aportes en materia de realismo social —realismo provocativo y de corte naturalista— que su novela El roto trató

7 JEB, citado por Francisco Coloane en su prólogo a la edición de Obras escogidas de Joaquín Edwards Bello, 1971, p. 19.

${ }^{8}$ JEB, citado por Francisco Coloane en su prólogo a la edición de Obras escogidas de Joaquín Edwards Bello, 1971, p. 19, reproduciendo la conversación sostenida por Alfonso Calderón con JEB el 28 de mayo de 1967.

${ }^{9}$ Juan Manuel Vial, “Edwards Bello: Descubriendo a Nuestro Genio Universal”, 2010.

${ }^{10}$ Pedro Gandolfo, “ El Secreto de lo Chileno”, 2009. 
de introducir en la literatura chilena en 1920. En esto el novelista fue fiel a sus observaciones, a su costumbre de moverse en distintos ambientes y a su declarada fascinación por los sectores más ocultos de la ciudad. El roto se ambienta básicamente en un prostíbulo del barrio Estación Central. Pero su mirada sobre ese mundo está lejos de ser documental. Después de todo, él sigue siendo un pije que mira desde afuera y desde arriba. "Su realismo, que constituye un grande esfuerzo artístico, 'chocará' a muchos. Pero, ¿quién podrá con justicia reprocharle al cirujano la libertad con que desnuda al enfermo, si lo que busca es sanarlo"11, lo defendía con más pudor del necesario en esa época el cura Omer Emeth en El Mercurio. Pedro Nolasco Cruz, que entendía la crítica literaria como "una manifestación razonada del buen gusto", fue bastante más severo con la obra y mezclando consideraciones literarias, sociales y éticas, simplemente la consideró vulgar y abominable ${ }^{12}$.

"Joaquín Edwards Bello —escribió Silva Castro— posee una viva sensibilidad para lo social. Quiere decir esto que los fenómenos que interesan a muchos le atraen con más fuerza que los que interesan a pocos. Hay un patente sentido demótico en su obra y en su vida. Odia al señorito, es decir, a lo que en Chile se llama joven bien o muchacho conocido. Ama al obrero honrado; cree con ganas en la generosidad y en la limpieza de alma del roto"13.

Alone, que fue el crítico literario chileno más penetrante del siglo $\mathrm{XX}$, lo caló bien, aunque tal vez sin mayor cariño: "Su sensibilidad a flor de piel, de desollado vivo, chocaba de continuo con el ambiente; era su llaga abierta y también su acicate. Quejarse constituía su fuerza. Siempre está confesando esa tragedia de expatriado en su tierra, de solitario en la multitud, acechado por fantasmas hostiles"14.

Es notable la enumeración con que el crítico continúa:

"Orgulloso y tímido, aristócrata y popular, delicado y agresivo, con la cabeza llena de ideas disparatadas como cohetes, realista hasta la

${ }^{11}$ Omar Emeth, citado por Francisco Coloane en su prólogo a la edición de Obras escogidas de Joaquín Edwards Bello, 1971, p. 23.

12 Pedro Nolasco Cruz, citado por Francisco Coloane en su prólogo a la edición de Obras escogidas de Joaquín Edwards Bello, 1971, p. 17.

${ }^{13}$ Silva Castro, citado por Francisco Coloane en su prólogo a la edición de Obras escogidas de Joaquín Edwards Bello, 1971, p. 24.

14 Alone, citado por Francisco Coloane en su prólogo a la edición de Obras escogidas de Joaquín Edwards Bello, 1971, p. 25. 
crudeza, nunca se entrega a la tentadora poesía que deja asomar, como si se le escapara, veteada de ternura compasiva y de una hipocresía que lo vuelve huraño.

"Vivió y ha muerto protestando"15.

Esta última faceta fue también la que más impresionó a Volodia Teitelboim en el homenaje que le rindió el año 68 en el Senado: “Aristócrata de cuna, define su casta como la clase que presta al 15\% mensual. No tenía pelos en la lengua y ni en la pluma, que manejó literalmente, como escritor a mano, con desdén de la máquina de escribir [...] Protestante eterno, ofició de crítico y reformador social por cuenta propia. Por temperamento fue un izquierdista solitario, nervioso, cascarrabias, que tuvo el orgullo de sus iras y nunca quiso tomar calmante para apagar la perpetua efervescencia de su espíritu mordaz"16.

Mientras que para Alone "su puesto en el diario fiscal lo ha limitado" y "sus audacias, sus protestas, no rebasan cierto ámbito"17, nuestra mayor poetisa, junto con exaltarlo al Olimpo de las letras chilenas, vio en él a un "tábano", a una conciencia alerta que siempre está aguijoneando esta sociedad hipócrita, adormecida y conformista ${ }^{18}$. Gabriela Mistral —que dicho sea de paso nunca perdió de vista las ventajas asociadas a la planilla fiscal y en esto era muy chilena - fue más allá y no se le ocurrió generosidad mayor que pedir públicamente para él una pega: "Debiera ser ya, como Alfonso Reyes o Víctor Belaúnde o como Gonzalo Zaldumbide, ministro de Chile en cualquier capital de habla española. Chile va a cumplir con él tarde, si cumple, y le desaprovechará sus briosos años de dionisismo mental, de creación jocunda" ${ }^{\prime 19}$.

La experiencia de leer hoy a Edwards Bello es tan intensa como sorprendente. Intensa porque sus crónicas tienen algo de torre de alta tensión: transportan corriente, vibran, sostienen cables que cruzan la inteligencia con el saber, la experiencia con la perversidad, la libertad de espíritu con el desacato, el absurdo con el humor. Y sorprendente

\footnotetext{
${ }^{15}$ Ibídem.

${ }^{16}$ Volodia Teitelboim, citado por Francisco Coloane en su prólogo a la edición de Obras escogidas de Joaquín Edwards Bello, 1971, p. 14.

${ }^{17}$ Alone, Historia personal de la literatura chilena, 1962, p. 253.

${ }^{18}$ Gabriela Mistral, citado por Francisco Coloane en su prólogo a la edición de Obras escogidas de Joaquín Edwards Bello, 1971, p. 21.

${ }^{19}$ Ibídem.
} 
porque en las mejores páginas que escribió está Chile. Está probablemente mucho más que si hubiese querido rastrearlo y capturarlo con cucalón y malla de sociólogo. Y está quizás porque en su mirada se combina una extraña manera de estar adentro y estar afuera. Quien está únicamente a un lado se pierde el otro. Edwards Bello, porque a veces quiso a Chile con locura y a veces el país le rebotó literalmente como pelota en el estómago, estuvo en ambos. Así las cosas, qué tiene de extraño que haya podido captar más.

\section{REFERENCIAS BIBLIOGRÁFICAS}

Alone. Historia personal de la literatura chilena. Santiago: Ed. Zig-Zag, 1962.

Borges, J. L. "The Art of Fiction”. Entrevistado por Ronald Christ. The Paris Review, $\mathrm{N}^{\circ} 40$ (Winter-Spring), 1967.

Edwards Bello, Joaquín. En torno al periodismo y otros asuntos. Selección, ordenación y prólogo de Alfonso Calderón. Santiago: Ed. Andrés Bello, 1969.

- Obras escogidas. Colección Premios Nacionales de Literatura. Presentación de Francisco Coloane. Santiago: Ed. Andrés Bello, 1971.

- Antología de familia. Prólogo y selección de Jorge Edwards. Santiago: Editorial Sudamericana, 2002.

- Crónicas reunidas 1921-1925 Vol. I. Edición y prólogo de Roberto Merino. Santiago: Ediciones UDP, 2008.

Crónicas reunidas 1926-1931 Vol. II. Edición de Roberto Merino y prólogo de Héctor Soto. Santiago: Ediciones UDP, 2009.

Gandolfo, Pedro. "El Secreto de lo Chileno. El Mercurio de Santiago, cuerpo Artes y Letras, 27 de diciembre de 2009.

Vial, José Manuel. “Descubriendo a Nuestro Genio Universal”. Diario La Tercera, 2 de enero de 2010. Santiago. 